\title{
Experimental and Numerical Study on Effect of Weld Reinforcement on Angular Distortion of SAW Square Butt Welded Plates
}

\author{
H. K. Narang*, M. M. Mahapatra**, P. K. Jha***, PVSS Sridhar****, and P. Biswas****, ${ }^{*}$ \\ *Mechanical Engineering Department, National Institute of Technology, Raipur, 492010, India \\ **School of Mechanical Sciences, Indian Institute of Technology, Bhubaneswar, 751013, India \\ ***Mechanical and Industrial Engineering Department, Indian Institute of Technology, Roorkee, 247667, India \\ ****Mechanical Engineering Department, Indian Institute of Technology, Guwahati, 781039, India
}

†Corresponding author : pankaj.biswas@iitg.ernet.in

(Received November 15, 2017 ; Revised January 10, 2018 ; Accepted February 26, 2018)

\begin{abstract}
Weld reinforcements play vital role in controlling different formation of inherent strains in the heat-affected zone in arc welded joints. It is desirable to have adequate weld reinforcements on both the top and bottom sides of butt joint such that shrinkage force effects of both the reinforcements would be cancelling the angular distortion. In this study, it has been established by experiments that acceptable top and bottom weld reinforcements can be achieved and angular distortion can be controlled in square butt joints through submerged arc welding (SAW) done from both the sides with accurate control of welding process parameters. Such process does not require use of costly backing strip and instead a flux bed can be used for the purpose. Modeling of the process was also carried out using 3-D thermomechanical finite element (FE) analysis. Moving distributed heat source, weld reinforcements on top and bottom side, weld deposition in each welding pass and temperature dependent thermos-physical properties were used in the thermomechanical analysis for predicting the temperature profiles and angular distortion patterns The numerically predicted temperature distribution and distortion patterns indicated close agreement with the experimentally observed results.
\end{abstract}

Key Words : Reinforcement, Moving heat source, Finite element, Thermal analysis, Nonlinear, Elasto-plastic analysis, Distortion

\section{Introduction}

Advancements in arc welding simulation have made it possible to include the finer details of welding experiments such as distortion control measures in 3-D modeling. However, in earlier days, 3-D welding problem simulations were conducted by two dimensional approximation for predicting thermal history and distortions ${ }^{1-3)}$. Although it is known that weld bead reinforcements have profound effects on the welding deformation, in earlier works, the effects of weld bead reinforcements were neglected. Researchers such as Michaleris and DeBiccari ${ }^{4)}$ had proposed a model of decoupled approach for predicting welding induced buckling in panel structure. They carried out the analysis in structural steel by considering kinematic hardening model $^{4)}$. The effect of hardening model on weld simulation was also investigated by Muransky et al..$^{5)}$ The welding simulation complexities with respect to the material model beyond yielding were discussed in detail by Lindgren ${ }^{6-7)}$ and suitability of 3-D model was advocated by investigators ${ }^{8}$. During arc welding, the constraints play a vital role in controlling the distortion and the effect of mechanical constraint on distortion was investigated by Park et al. ${ }^{9}$. The effect of constraints such as clamping on weld distortion was investigated in detail by Shenk et al. ${ }^{10)}$. The effect of tack weld constraints and process parameters on angular distortion of SAW fillet joints was investigated by Mahapatra et al. 11) using 3-D finite element (FE) analysis. Effect of weld tacking on weld distortion was also studied in detail by Camilleri et al. ${ }^{12)}$ Use of welding procedures to minimize the angular distortion in SAW butt joints was

Journal of Welding and Joining, Vol.36 No.2(2018) pp48-59

https://doi.org/10.5781/JWJ.2018.36.2.8 
investigated by Mahapatra et al. ${ }^{13)}$ by utilising moving distributed heat source in 3-D finite element analysis. The welding heat input and nature of heat source affects the weld dimension and stress built up in the joint. Kannengiesser et al. ${ }^{14)}$ had investigated the effect of heat input on induced stress build up in high strength steel welded joint under restraint conditions. High computing power, memory is a requirement for the 3-D computation of welding distortion patterns. Investigators have used both local and global approaches for distortion prediction. An overview of simplified approached for residual stress estimation in different welded joints were given by Bhatti and Barsoum ${ }^{15)}$. The simplified sequential thermomechanical approaches were developed with moving heat source for realistic simulation of welding process and validated with butt, fillet and tube flange joints ${ }^{15}$. Tsirkas et al. $^{16)}$ predicted the distortion in a global model by utilizing the plastic strains obtained from a local model. For actual 3-D thermomechanical simulation of welding process moving distributed heat source, temperature dependent thermosphysical properties and weld metal depositions have been considered in the numerical models ${ }^{17)}$. Use of a suitable welding heat source model is the most important aspect of welding thermal analysis. Fanous et al., ${ }^{18)}$ had used distributed and circularly spread moving heat source in the 3-D FE model to predict the thermal history and distortion. Welding distortion simulation is computationally demanding and recent advancement in this field of research is the "inherent deformation method" as proposed by Wang et al. ${ }^{19)}$. The inherent deformations method is claimed to be computationally less demanding and preferable for large deformation and has been well established by Murakawa and co-workers over the years ${ }^{20-25)}$. Nevertheless, the welding deformation is condition specific and the weld reinforcement geometries are important consideration for weld thermomechanical analysis ${ }^{26)}$ for predicting the transient temperature distribution and residual deformation. SAW is a flux covered arc welding system and widely utilized in heavy industries for producing thick welds. The SAW is also conveniently utilized for the purpose of repair welding and cladding. The welding distortions of thin plates are corrected easily as compared to thick plates. Since SAW is primarily used for welding of thick plates, it is important to take preventive steps during welding itself to reduce the distortion as distortion correction measures for thick joints are quite costly. One of the methods that can be used in SAW to reduce distortion is the single pass double side welding where the welding is done from both sides of the joint to achieve adequate weld reinforcements on both sides.
Though SAW process is a very popular joining technique in heavy structural fabrications but almost no similar works are observed which investigated the effect of weld reinforcements on distortions of single pass both side SAW square butt joints (i.e. joints without any edge preparation) using 3D FE analysis. So, there is a need to develop a three-dimensional model and suitable experimental procedure for finding out the distortions in single pass SAW butt-joints welded from both sides.

This present study dealt with single pass double side SAW square butt welding of $12 \mathrm{~mm}$ thick structural steel plates by using a flux bed. Use of costly backing strip was thus eliminated The SAW square butt joints were welded from both side sequentially. The idea was to have adequate weld reinforcement on both the sides of square butt joints such that the shrinkage forces on both the sides would cancel out each other resulting in minimized angular distortion. The phenomenon is shown in a simple schematic in Fig. 1 (a) and (b) which indicates cross sections of two square butt welds with different weld reinforcements. Fig. 1 (a) indicates greater top side shrinkage force (TSF) due to larger weld deposition at the top side leading to higher angular distortion. The topside shrinkage force (TSF) and bottom side shrinkage force (BSF) are nearly equal for the butt welded joint shown in Fig. 1 (b) resulting in lower angular distortion.

\section{Modeling methodology}

The 3-D finite element analyses of SAW butts were

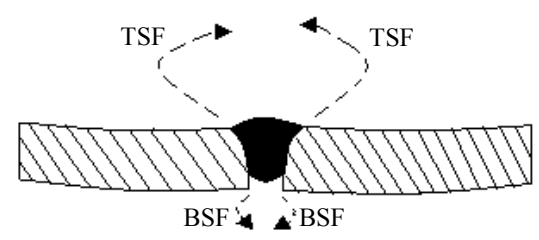

(a)

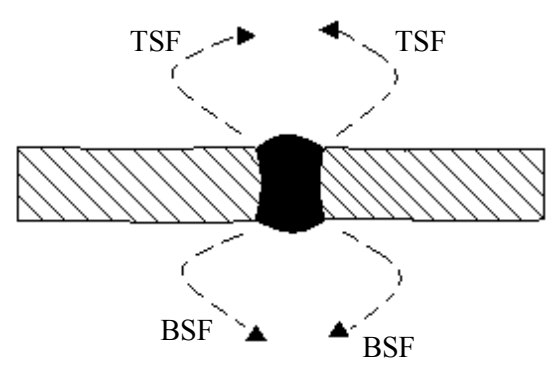

(b)

Fig. 1 (a) A butt joint with greater top side shrinkage force (TSF) due to greater weld deposition at the top side; (b) A butt joint with near equal top side shrinkage force (TSF) and bottom side shrinkage force (BSF) 
carried out considering the following: (1) heat source with movement as per welding speed, (2) temperature dependent thermos-physical properties, (3) joint geometry such as upper bead and lower bead reinforcements in the modeling, and (4) incorporation of suitable material model for the elastic-plastic behavior of the structural steel weld and base metal. The transient thermal history was compared with the experimental data such as thermocouple readings and macrostructure zones' boundary. Transient thermal and non-linear elasto-plastic thermos-mechanical analyses were performed to predict the temperature distribution in each welding pass and angular distortion of the SAW square butts. The developed methodology was also compared with the patterns of distortion obtained from experiment. The chemical composition of the base metal used for SAW is given in the earlier publication ${ }^{27}$.

The heat source used in this present work was considered as distributed heat flux. Varying welding parameters such as weld traverse rate, current and voltage were used in the experiment. The transient temperature data were measured on both top and bottom sides of the plate using thermocouples for each welding pass away from the weld center. The temperature profiles obtained from transient thermal analysis were compared with measured thermocouple readings. The heat flux used in FE model was considered as a Gaussian distributed heat flux as stated in equation (1):

$$
\mathrm{q}(\mathrm{r})=\frac{3 \mathrm{Q}_{\mathrm{e}}}{\pi \overline{\mathrm{r}}^{2}} \exp \left[-3\left(\frac{\mathrm{r}}{\overline{\mathrm{r}}}\right)^{2}\right]
$$

where $\bar{r}$ is characteristic radius of heat source where $95 \%$ of heat flux is concentrated ${ }^{27-29)}$ and

$Q_{e}=\eta_{V I}=$ power of welding arc, $\mathrm{W}$

$\eta=$ welding arc efficiency

I \& $V=$ arc current in 'amp' and arc voltage 'volt' respectively.

\section{Thermal modeling of SAW bead-on-plates}

The 3-D FE analysis of the SAW bead-on-plates were carried out considering the following: (i) moving co-ordinate heat source, (ii) temperature dependent material properties, (iii) bead geometry such as reinforcement on both sides of joints. The moving heat source model was initially tested for SAW butt bead-on-plates for predicting the thermal histories and macrostructure boundary zones. For SAW bead-on-plates, the temperature distribution were fairly matched with the experimentally obtained thermal profile such as thermocouple readings and macrostructure zones' boundary. Once the moving

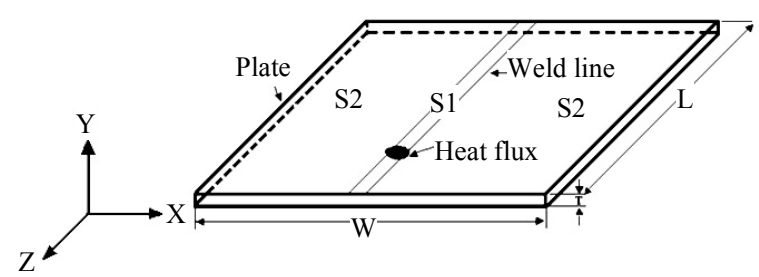

Fig. 2 Schematic of SAW bead-on-plate

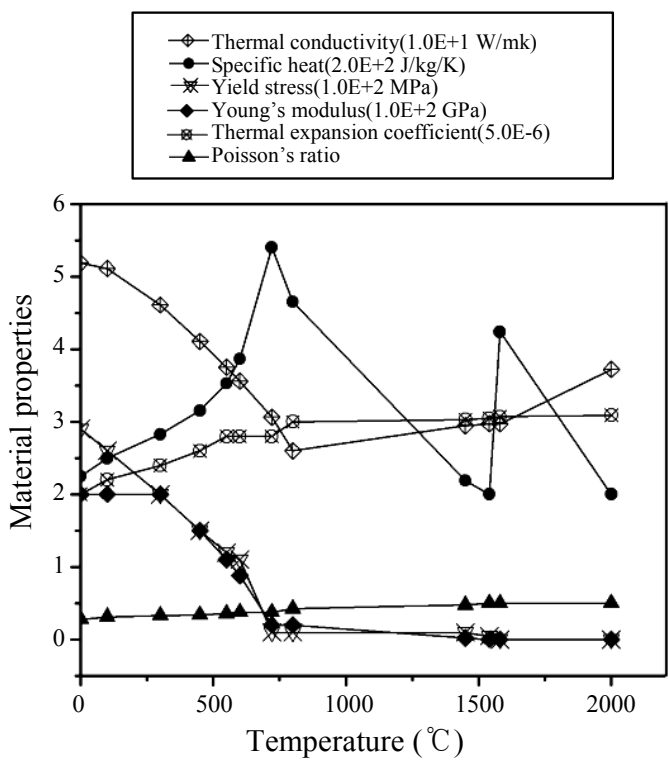

Fig. 3 Material properties used in finite element analysis

heat source model's effectiveness was established for SAW bead-on-plates, the modelingl technique was further extended for thermomechanica analysis of square butt joints.

The top side temperatures of bead-on-plate welds, at distance from the weld, were measured by K-type thermocouples. Due to the flux cover over SAW weld bead and arc it is impossible to measure the SAW arc spread. Hence arc radius of each but-bead-on plate weld was estimated ${ }^{11,17,27)}$ based on the electrode diameter and dimension of weld bead reinforcement. The schematic of butt-bead-on plate is shown in Fig. 2.

The thermos-physical material properties ${ }^{26-29)}$ used in the analysis to estimate temperature profiles and distortions are presented in Fig. 3. The constant material density used in the analysis was taken as $7850 \mathrm{~kg} / \mathrm{m}^{3}$ ${ }^{26-29)}$. The liquidus $\left(\mathrm{T}_{\text {liquidus }}\right)$ and Solidus $\left(\mathrm{T}_{\text {solidus }}\right)$ temperatures of the base material were considered as $1500{ }^{\circ} \mathrm{C}$ and $1450{ }^{\circ} \mathrm{C}$ respectively ${ }^{11)}$.

Natural Newtonian convective cooling was assumed for all the surfaces of the welded joint except the weld region. To account for other losses, arc efficiency $(h=$ $0.90)$ was taken into consideration ${ }^{11,27)}$. The thermal governing equation in an isotropic solid is given by: 


$$
\frac{\partial}{\partial x}\left[K \frac{\partial T}{\partial x}\right]+\frac{\partial}{\partial y}\left[K \frac{\partial T}{\partial y}\right]+\frac{\partial}{\partial z}\left[K \frac{\partial T}{\partial z}\right]=\rho c \frac{\partial T}{\partial t}
$$

\subsection{Boundary conditions}

Initial condition: A specified room temperature was considered for the entire surface of welding plate

$$
T=T_{a} \text { for time ' } t \text { ' }=0
$$

where $T_{a}$ is the surrounding temperature. As the weld area is completely covered by flux granules in SAW, no convectional heat transferee was considered for the weld region. For second and third boundary conditions, the energy balance criteria has been considered at the work surface.

First boundary condition: The specified heat flow acting over the surface

$$
\{q\}^{T}\{n\}=-q_{\text {sup }} \text { on the weld zone surface } S_{l} \text { for time ' } t \text { '>0 }
$$

where, $\left(q_{\text {sup }}\right)$ is a specified heat flow supplied from an external welding arc over the instantaneous surface $S_{I}$ (weld zone) of work.

$2^{\text {nd }}$ boundary condition: Heat loss over the surface other than welding region $S_{2}$ has been specified by Natural Newton law of convection which is as below:

$$
q_{n}=q_{\text {con }}
$$

or

$$
\{q\}^{T}\{n\}=h_{f}\left(T-T_{\infty}\right) \text { on } S_{2} \text { for time } t>0
$$

where $S_{2}$ represents the surface of work other than weld zone exposed and

$$
\left(q_{c o n}\right)=\text { convection heat loss. }
$$

Table 1 Composition of the structural steel used in the experiments

\begin{tabular}{|c|c|c|c|c|c|c|c|}
\hline $\mathrm{C} \%$ & $\mathrm{Si} \%$ & $\mathrm{Mn} \%$ & $\mathrm{P} \%$ & $\mathrm{~S} \%$ & $\mathrm{Ni} \%$ & $\mathrm{Cr} \%$ & $\mathrm{Fe} \%$ \\
\hline 0.160 & 0.177 & 0.453 & 0.179 & 0.069 & 0.132 & 0.015 & 98.841 \\
\hline
\end{tabular}

Table 2 Process parameters of SAW bead-on-plates and weld dimensions

\begin{tabular}{|c|c|c|c|c|c|}
\hline $\begin{array}{c}\text { Sample } \\
\text { No. }\end{array}$ & $\begin{array}{c}\text { Welding } \\
\text { Current } \\
\text { (A) }\end{array}$ & $\begin{array}{c}\text { Welding } \\
\text { Voltage } \\
(\mathrm{V})\end{array}$ & $\begin{array}{c}\text { Traverse } \\
\text { Speed } \\
\text { [WS }] \\
(\mathrm{mm} / \mathrm{sec})\end{array}$ & $\begin{array}{c}\text { Bead } \\
\text { Height } \\
(\mathrm{mm})\end{array}$ & $\begin{array}{c}\text { Bead } \\
\text { width } \\
(\mathrm{mm})\end{array}$ \\
\hline 1 & 450 & 29 & 5.56 & 3.07 & 17.25 \\
\hline 2 & 475 & 32 & 6.94 & 2.83 & 16.88 \\
\hline 3 & 525 & 36 & 8.33 & 2.16 & 17.53 \\
\hline
\end{tabular}

Temperature dependent enthalpy was used as one of the material property for avoiding the sharp change in the value of specific heat. The chemical composition of structural steel used in the experiment is given in Table 1. The process parameters of SAW bead-on-plates are indicated in Table 2. The SAW bead-on-plates FE modelling geometries with different weld reinforcements together with the etched weld cross-sections are shown in

\subsection{Result of thermal analysis of SAW bead-on-plates}

The result of thermal analysis for Job 1 as per parameters stated in Table 2 is presented in Fig. 5 (a). It is observed that the peak temperature exceeds $2550{ }^{\circ} \mathrm{C}$ at the middle of the weld as indicated in Fig. 5(a). The temperature during welding was measured using K-type thermocouples. The thermocouples were connected to AGILENT 34972A data logger device with 20 channels multiplexer. This data logging device was connected to a PC and the temperature at different locations were

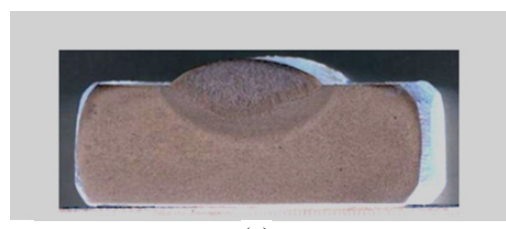

(a)

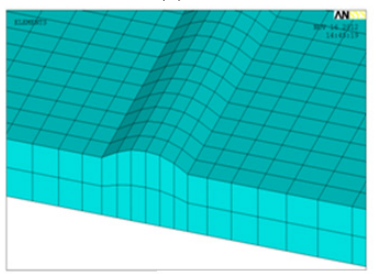

(d)

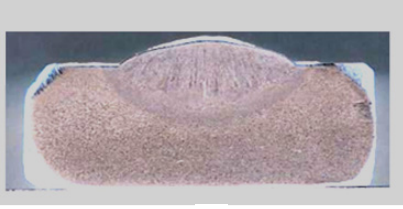

(b)

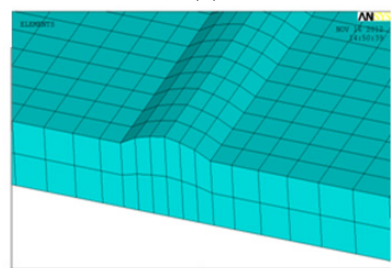

(e)

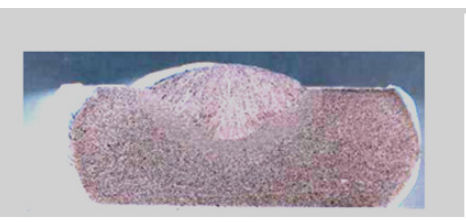

(c)

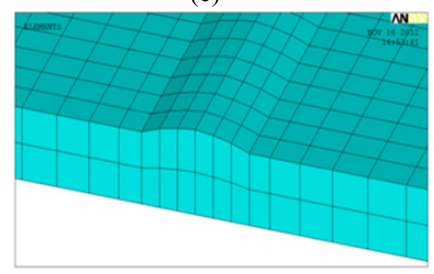

(f)

Fig. 4 The etched weldment crosses sections of: (a) Sample 1; (b) Sample 2; (c) Sample 3 and model \& meshing of butt-bead-on with weld reinforcement of (d) Sample 1; (e) Sample 2; (f) Sample 3 


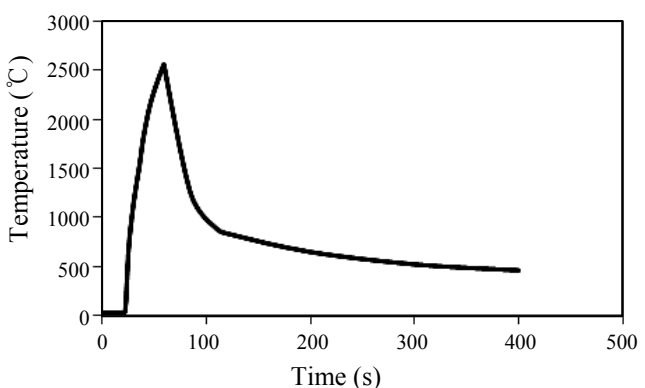

(a)

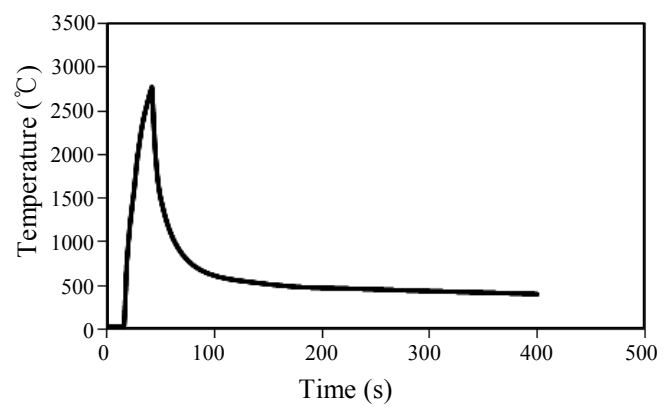

(c)

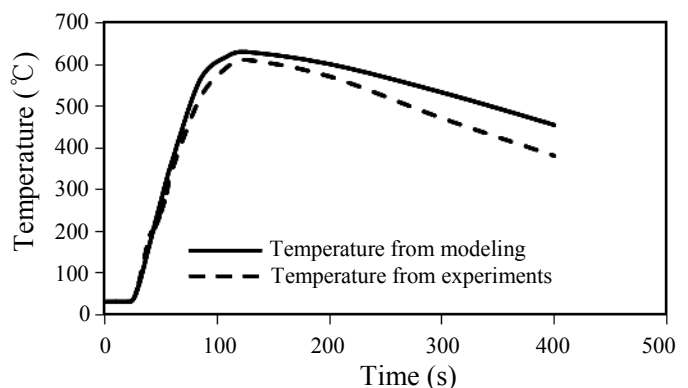

(b)

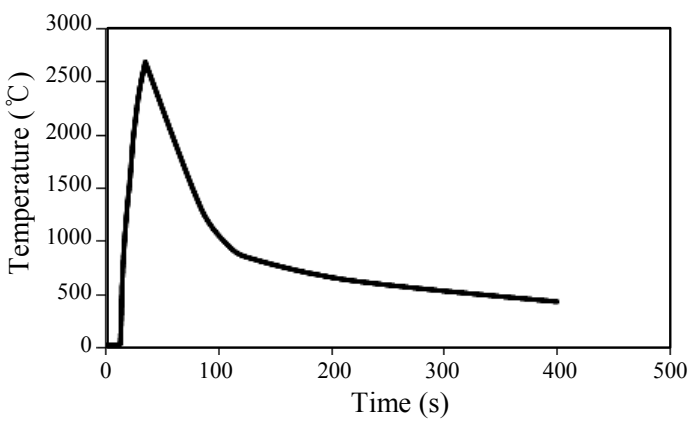

(d)

Fig. 5 (a) Peak temperatures distribution of Job 1; (b) Comparison of temperatures profiles 22mm away from the weld centre; (c) Peak temperatures distribution of Job 2 and (d) Peak temperatures distribution of Job 3

measured \& recorded with time. Time dependent temperature data during welding at $22 \mathrm{~mm}$ from the weld center were noted by thermocouples. The experimentally observed and numerically obtained temperature profiles $22 \mathrm{~mm}$ away from the weld centre are plotted in Fig. 5(b) and close agreement is observed between the two with a variation of $6 \%$ only in case of peak temperatures.

The result of thermal analysis for Job 2 is presented in Fig. 5 (c). It is observed that the peak temperature exceeds $2781{ }^{\circ} \mathrm{C}$ at the middle of the weld as indicated in Fig. 5 (c). The temperatures observed for Job 2 is higher than that of Job 1 due to higher current and voltage. Similar trend was also observed for Job 3 in Fig. 5 (d) where the peak temperature attains higher values than that of Job 1. The temperature distributions obtained from the model was analysis to predict the boundary of fusion zone in terms of weld width and depth of penetration. The numerically predicted and experimental measure zones based on the peak temperatures attained are given in Table 3.
It is also observed that the experimentally observed temperatures distributions fairly matched with and numerically predicted temperatures distributions. The moving distributed heat source based thermal modeling of SAW bead-on-plates proved to be successful in predicting the temperature distribution and macrostructure zones.

\section{Thermomechanical analysis}

\subsection{Experimental details}

The experimental setup and the schematic of weld geometry cross-section are shown in Fig. 6 (a) and (b). The specification of the filler wire used was AWS EH-14, Grade C, $4 \mathrm{~mm}$ diameter. The SAW flux used was granular, basic and fluoride. The tack welding was applied at two points which are $5 \mathrm{~mm}$ away from the both edge (ends) of the plates. The welding was done from both sides of plates.

Table 3 Numerical and experimental SAW bead-on-plate weld dimensions

\begin{tabular}{|c|c|c|c|c|c|c|c|}
\hline $\begin{array}{c}\text { Job } \\
\text { No. }\end{array}$ & $\begin{array}{c}\text { Numerical peak } \\
\text { temperature } \\
\left({ }^{\circ} \mathrm{C}\right)\end{array}$ & $\begin{array}{c}\text { Measured } \\
\text { bead width } \\
(\mathrm{mm})\end{array}$ & $\begin{array}{c}\text { Estimated } \\
\text { bead width } \\
(\mathrm{mm})\end{array}$ & $\begin{array}{c}\text { \% Error of } \\
\text { bead width } \\
\text { prediction }\end{array}$ & $\begin{array}{c}\text { Measured } \\
\text { depth of } \\
\text { penetration }\end{array}$ & $\begin{array}{c}\text { Estimated } \\
\text { depth of } \\
\text { penetration }\end{array}$ & $\begin{array}{c}\text { \% Error of } \\
\text { depth of } \\
\text { penetration }\end{array}$ \\
\hline 1 & 2550 & 15.25 & 13.9 & -8.85 & 4.25 & 3.95 & -7.05 \\
\hline 2 & 2781 & 16.88 & 13.68 & -18.95 & 4.38 & 4.34 & 0.91 \\
\hline 3 & 2714 & 17.53 & 14.44 & -17.62 & 5.07 & 4.87 & -3.94 \\
\hline
\end{tabular}




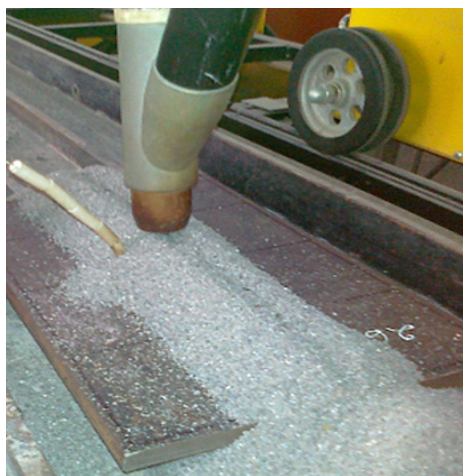

(a)

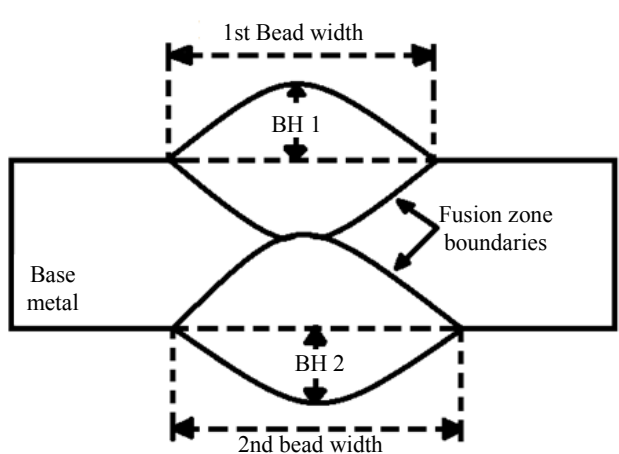

(b)

Fig. 6 (a) Experimental setup of SAW; (b) Schematic of a single pass double side SAW weldment indicating the bead widths and reinforcement heights (BH $1 \& \mathrm{BH} 2)$ of each weld pass

Table 4 Trial experimental runs for achieving depth of penetration more than $50 \%$ of plate thickness

\begin{tabular}{|c|c|c|c|c|}
\hline $\begin{array}{c}\text { Trial } \\
\text { No. }\end{array}$ & $\begin{array}{c}\text { Voltage } \\
\text { (volt) }\end{array}$ & $\begin{array}{c}\text { Current } \\
(\mathrm{amp})\end{array}$ & WS (mm/s) & $\begin{array}{c}\text { Depth of penetration } \\
\text { in \% of thickness }\end{array}$ \\
\hline 1 & 32 & 525 & 6.9 & 41.708 \\
\hline 2 & 32 & 550 & 5.55 & 46.167 \\
\hline 3 & 32 & 600 & 5.55 & 56.95 \\
\hline
\end{tabular}

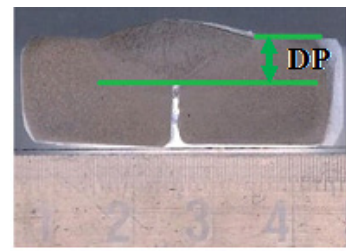

(a)

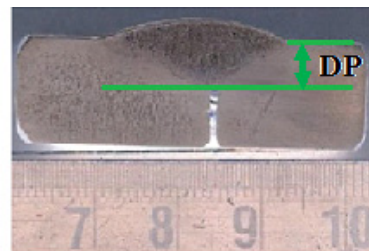

(b)

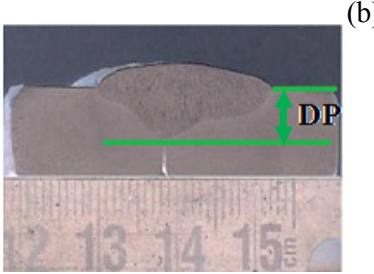

(c)

Fig. 7 Effect of process parameters on (DP) depth of penetration: (a) \& (b) Depth of penetration of Trail 1 \&2 less than $50 \%$ of plate thickness leading to entrapped slag in the joint; (c) Depth of penetration more than $50 \%$ of plate thickness for Trial 3 (Table 4)
In order to avoid the occurrence of slag inclusion in the joint, it was required that in each pass of welding more than $50 \%$ of depth of penetration in terms of plate thickness $(12 \mathrm{~mm})$ is achieved. To accomplish the task a series of trial experiment runs were made and penetration achieved was measured as stated in Table 4. It is observed from Table 4 and Fig. 7 that with 32 V, $600 \mathrm{~A}$ and welding speed of $5.5 \mathrm{~mm} / \mathrm{sec}$ more that $50 \%$ depth of penetration in terms of plate thickness could be achieved. Since the depth of fusion is less than $70 \%$ of the joint thickness, no extra arrangement such as backing strip was required to support the molten weld metal. Instead a flux bed was quite suitable for the purpose. This minimized the production cost. After each pass of welding the root was cleaned of slag with a wire brush and welding continued for the second side pass. Based on the trial experiments, the parameters of square butts were decided and presented in Table 5.

The process is schematically shown in Fig. 8. The dimensions of each plate were $300 \mathrm{~mm} \times 100 \mathrm{~mm} \times 12 \mathrm{~mm}$. The plate surface was marked with grid points along the plate edges as shown in Fig. 8 to measure the angular distortion. In the finite element analysis, the displacements of these points are regarded as the nodal displacement. The two welding heat sources used in both the weld passes on both sides are also shown in Fig. 8. Schematic of a single pass double side SAW butt weld in shown in Fig. 6 (b). The single pass double side SAW square butt joint process parameters are stated in

Table 5 Single pass double side SAW square butt joint process parameters

\begin{tabular}{|c|c|c|c|c|c|c|c|c|c|}
\hline $\begin{array}{c}\text { Sample } \\
\text { No }\end{array}$ & $\begin{array}{c}\text { Current } \\
(\mathrm{amp})\end{array}$ & $\begin{array}{c}\text { Voltage } \\
(\mathrm{volt})\end{array}$ & $\begin{array}{c}\text { WS } \\
(\mathrm{mm} / \mathrm{s})\end{array}$ & $\begin{array}{c}\text { BW1 } \\
(\mathrm{mm})\end{array}$ & $\begin{array}{c}\text { BW2 } \\
(\mathrm{mm})\end{array}$ & $\begin{array}{c}\text { H1 } \\
(\mathrm{mm})\end{array}$ & $\begin{array}{c}\text { H2 } \\
(\mathrm{mm})\end{array}$ & $\begin{array}{c}\text { Total area } \\
(\mathrm{mm})\end{array}$ \\
\hline 1 & 600 & 30 & 7.22 & 17.5 & 18.69 & 1.6 & 2.38 & 214.12 & 0.532 \\
\hline 2 & 615 & 32 & 7.78 & 20.11 & 20.08 & 1.72 & 2.43 & 213.95 & 0.467 \\
\hline 3 & 625 & 34 & 7.78 & 22.21 & 21.5 & 1.73 & 2.65 & 207.32 & 0.621 \\
\hline
\end{tabular}




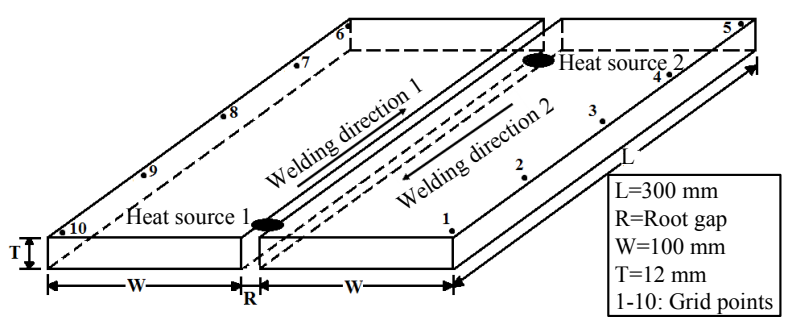

Fig. 8 Schematic of single pass double side SAW square butt joint with two moving heat sources and grid points for measuring distortion

the Table 5. To measure the distortion, the specified locations were marked on the tack-welded plates. A linear variable transformer (LVDT) was used for measuring grid point displacement. After completion of welding, the displacements of predefined marked locations were noted. The experimental distortions were calculated by subtracting the pre-welding readings from after welding readings. The vertical displacements of the marked locations of the joints were compared with the FE analysis results.

\subsection{Thermal analysis of single pass double side SAW square butt joints}

The procedure of moving Gaussian distributed heat source adopted for the FE thermal analysis of SAW bead-on-plates proved it's adequacy in predicting the temperature distribution and boundaries of fusion zone. The model was further extended for predicting the temperature distributions in case of single pass double side SAW square butt joints. The idea was to achieve adequate weld reinforcement on both sides of the plates to minimize angular distortion and to avoid the use of costly backing strip. Since in SAW the spread of arc is not visible, it has to be estimated. In the present investigation the arc radii were estimated based on the weld reinforcement dimension and subsequently used in the modeling for the prediction of transient temperature distribution ${ }^{11,27)}$. The resulting temperature profiles were further compared with the experimentally obtained profiles. In the FE analysis the moving heat flux was applied as given in equation (1). Here the arc energy transfer efficiency $(\eta)$ of $90 \%$ was used ${ }^{11,27)}$. The boundary conditions used for the SAW square butt thermal modeling is as described in equations 2-5. The polished and etched weldment cross sections of Jobs 1-3 are presented in Fig. 9. The meshing and model of the jobs are presented in Fig. 10. The weld zone is finely meshed with gradual coarsening of meshing away from the weld zone. In the FE model, the dimensions of welds (weld width and reinforcement) were incorporated as
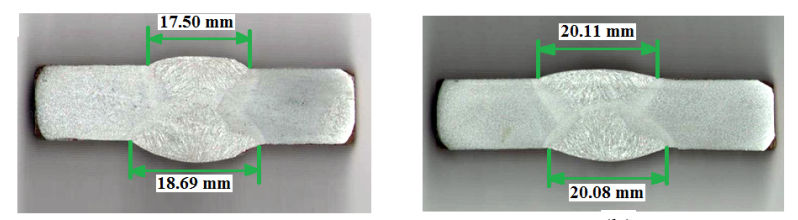

(a)

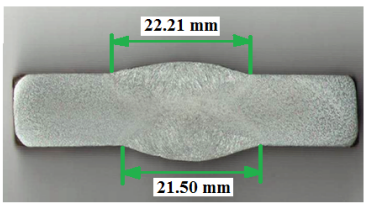

(c)

Fig. 9 Macrostructure of SAW welds: (a) Weld cross section of Job 1 (Table 5); (b) Weld cross section of Job 2 (Table 5); (c) Weld cross section of Job 3 (Table 5)

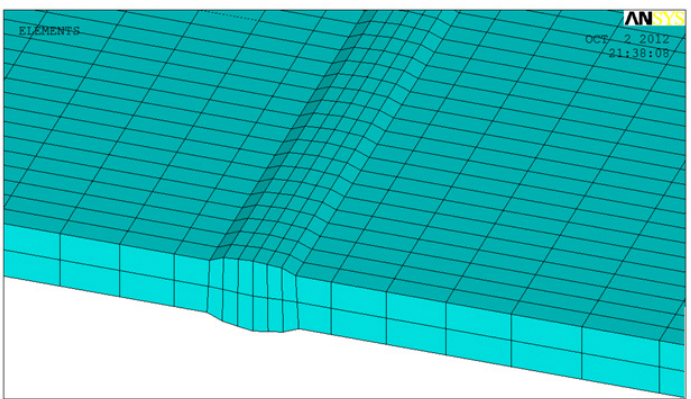

(a)

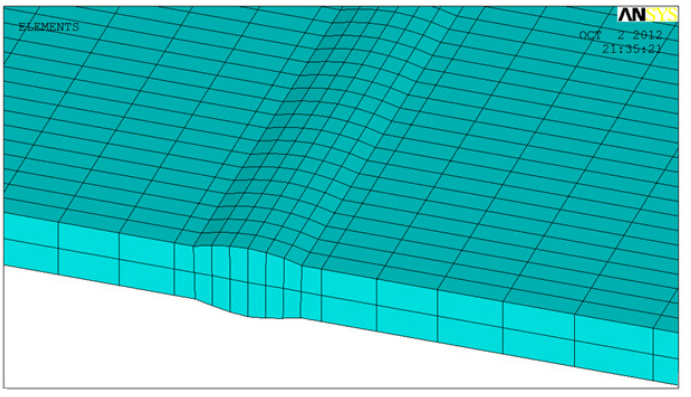

(b)

Fig. 10 Modeling the SAW square butt joints according to the weld reinforcement height and width: (a) Model and meshing of Sample 1; (b) Model and meshing of Sample 2

indicated for Jobs 1-2 in Fig. 10. Eight node brick element was used in the thermal model. For the structural model eight node brick element was also used for good compatibility.

The peak temperatures distribution for the first pass (first side weld) of Sample 1 (Table 5) is shown in Fig. 11 (a). It is observed that the temperatures rises up to $2000{ }^{\circ} \mathrm{C}$ very rapidly and then cools down till $450 \mathrm{sec}$ onds up to nearly $250{ }^{\circ} \mathrm{C}$ and then the second pass welding starts. The fist pass weld is heated up to $700{ }^{\circ} \mathrm{C}$ from $250{ }^{\circ} \mathrm{C}$ soon after the second side welding starts as 


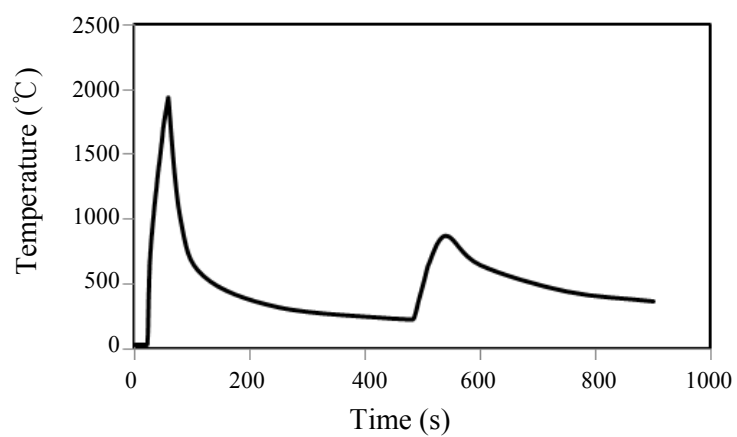

(a)

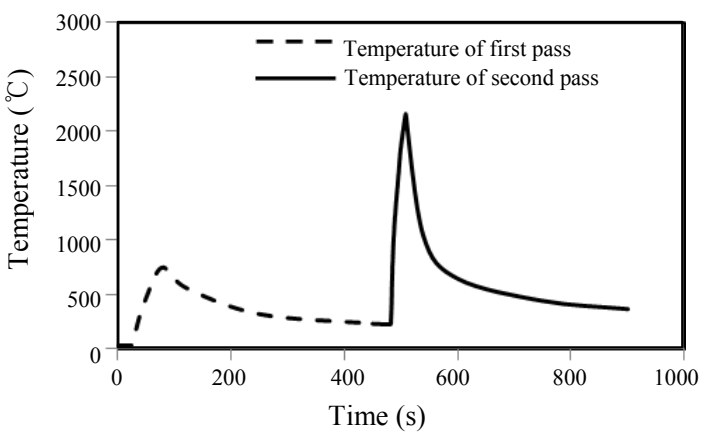

(b)

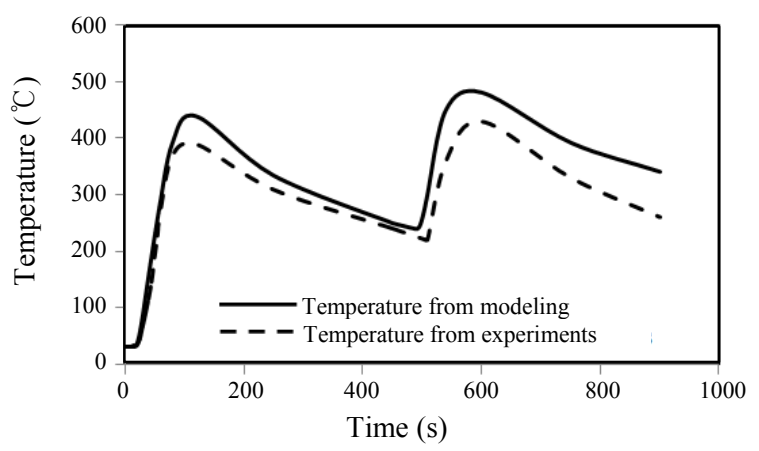

(c)

Fig. 11 (a) Peak temperature distribution along the first pass weld line of Job 1 due to first and second side welding, (b) Peak temperature distribution of Job 1 along the second side weld line due to second weld pass (the preheating effect of first side welding shown in dashed line) and (c) Comparison of experimental and numerically predicted temperature profile $22 \mathrm{~mm}$ from weld centre of Job 1

indicated in Figs. 11 (a). This is the post welding heat treatment of first pass weld by the second pass welding. The peak temperatures distribution of second side welding is shown in Fig. 11 (b) for Sample 1. The dashed line portion of the temperature curve in Fig. 11 (b) indicates preheating effect of first pass welding. Due to the preheating effect of first pass welding, the second pass weld experience a temperature rise and welding starts at around $250{ }^{\circ} \mathrm{C}$ instead of room temperatures. Comparison of experimental and numerically predicted temperature profile at $22 \mathrm{~mm}$ away perpendicular to the centre of weld of Sample 1 is shown in Fig. 11 (c). The temperature during welding was measured using K-type thermocouples. The thermocouples were connected to AGILENT 34972A data logger device with 20 channels multiplexer. It can be observed that the experimental temperature profiles agree fairly well with the predicted ones with a variation of $11 \%$ only in case of peak temperatures.

The peak temperatures distribution for the first pass (first side weld) of Sample 2 is shown in Fig. 12 (a). It is observed that the temperatures shoots up above $2000{ }^{\circ} \mathrm{C}$ rapidly and then cools down till 450 seconds up to nearly $300{ }^{\circ} \mathrm{C}$. The fist pass weld is heated up to $700{ }^{\circ} \mathrm{C}$ soon after the second side welding starts as indicated in Fig. 12 (a). The peak temperatures distribution of second side welding is shown in Fig. 12 (b) for Sample 2. The dashed line portion of the temperatures curve in Fig. 12 (a) indicates preheating effect of first pass welding. Due to the preheating effect of first pass welding, the second pass weld experience a temperature rise and welding starts at around $300{ }^{\circ} \mathrm{C}$ instead of room temperatures. Similar trend of first pass and second pass welding for Sample 3 are shown in Fig. 12 (c) \& (d) respectively. For Sample 1-3 (Table 5) the experimental and numerical temperature profiles compared fairly well.

\subsection{Structural analysis of single pass double side SAW square butt joints}

The welding time was divided into several load steps in the thermal analysis and the resulting thermal condition was considered as the load for the sequential non-linear elasto-plastic structural analysis. Further, in the structural analysis, kinematic work hardening was considered for the weld and base meta ${ }^{14,17,27,28)}$. Von Mises yield criterion and associative flow rule was also incorporated in the structural analysis ${ }^{4,17,27,28)}$. 3-D 8-nod- 


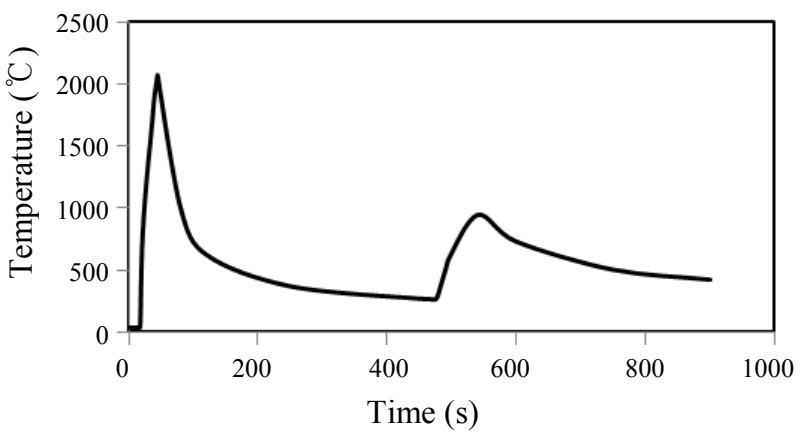

(a)

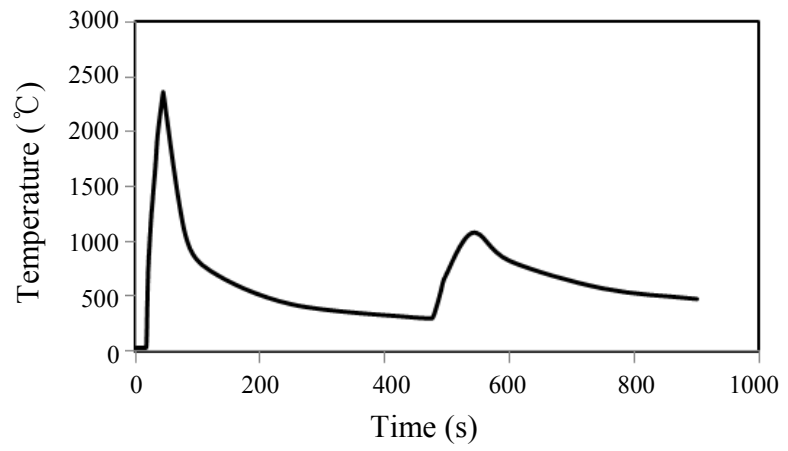

(c)

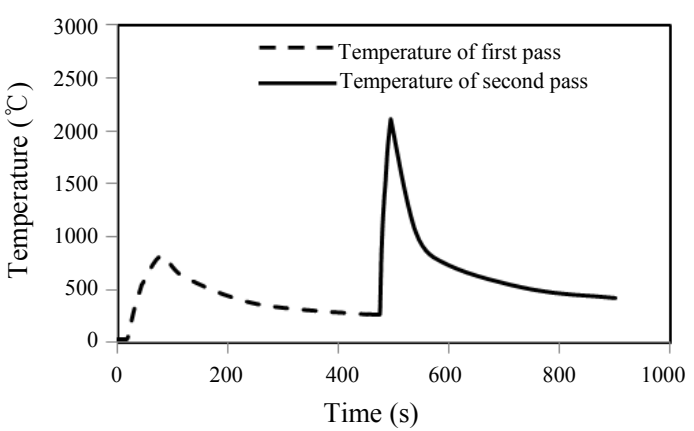

(b)

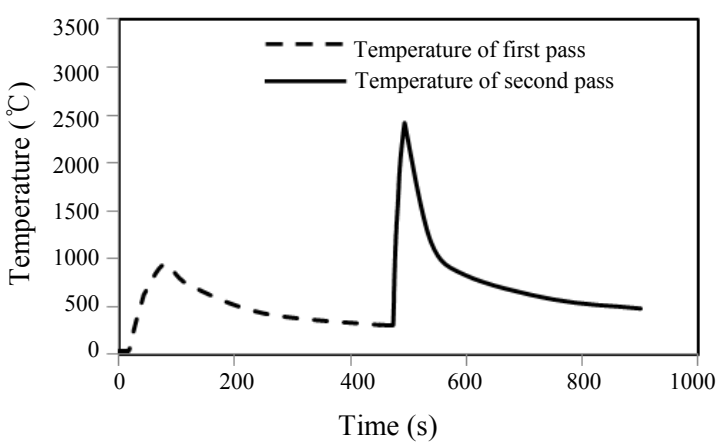

(d)

Fig. 12 (a) Peak temperature distribution along the first pass weld line of Job 2 due to first and second side welding, (b) Peak temperature distribution of Job 2 along the second side weld line due to second weld pass (the preheating effect of first side welding shown in dashed line), (c) Peak temperature distribution along the first pass weld line of Job 3 due to first and second side welding and (d) Peak temperature distribution of Job 3 along the second side weld line due to second weld pass (the preheating effect of first side welding shown in dashed line)

ed brick element was used in the thermal model. For the structural model eight node brick element was also used for good compatibility. The solution was obtained using FE package ANSYS ${ }^{30}$. The nonlinear thermo-mechanical analysis involved large displacements. In the structural analysis boundary conditions which prevented rigid body motions were imposed.

The distortion of Sample 1 expresses as the nodal deflection in ' $Y$ ' direction is shown in Fig. 13 (a). The nodal deflection patterns from the distortion model were compared with the grid point displacements of square butt joints. The nodal deflection in $\mathrm{Y}$ direction for Sample 2 and Sample 3 are shown in Fig. 13 (b) and (c) respectively. The comparative grid point displacement and nodal point deflection in Y direction of Sample 1 is presented in Fig. 14 (a). The comparative grid point displacements and nodal point deflections in $\mathrm{Y}$ direction of Job 2 and 3 are given in Fig. 14 (b) \& (c) respectively. It can be observed that there is close agreement between the measured and predicted value of distortion. Maximum distortion of $0.558 \mathrm{~mm}$ was predicted for Sample 3 while minimum angular distortion of $0.430 \mathrm{~mm}$ was predicted for Job 2. It is observed from the process parameter Table 5 that Sample 1 is having least values of welding current, voltage and traverse speed. The heat source in Sample 1 travels at less speed in comparison to Sample 2 and 3. This might be the reason for higher angular distortion of Sample 1 when compared to that of Sample 2. Maximum angular distortion was exhibited in Sample 3 than Samples 1 \& 2 due to higher welding current and voltage. Compared to single side square butt joints ${ }^{13,27)}$ the single pass double side square butt joints exhibited lower angular distortion due to adequate weld reinforcement on both the side of the joint.

\section{Conclusions}

From the thermomechanical analysis of single pass double side SAW square butt joints following conclusions can be drawn:

- A 3-D transient elasto-plastic thermo-mechanical FE model was successfully developed to study the thermal history and distortion of single pass double side SAW square butt joints by considering top and bottom reinforcement. The developed modeled matched fairly well with that of experimental results with an error of $6-11 \%$ only.

- To minimize the angular distortion, single pass double 


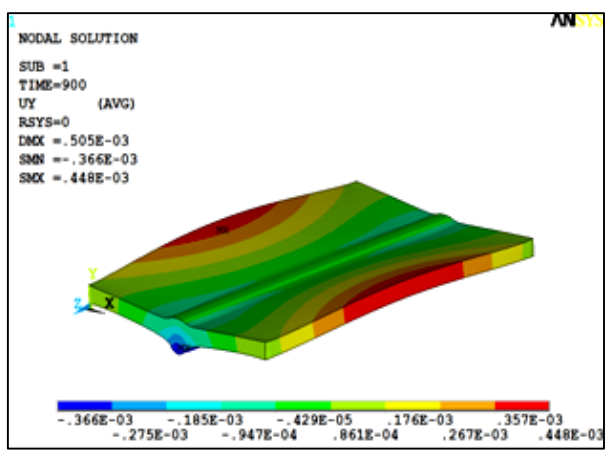

(a)

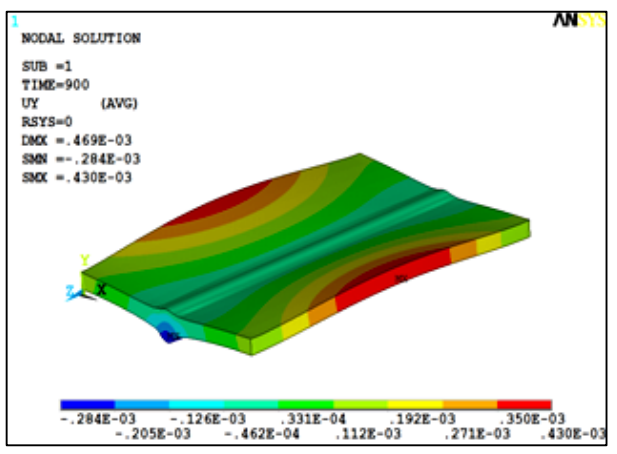

(b)

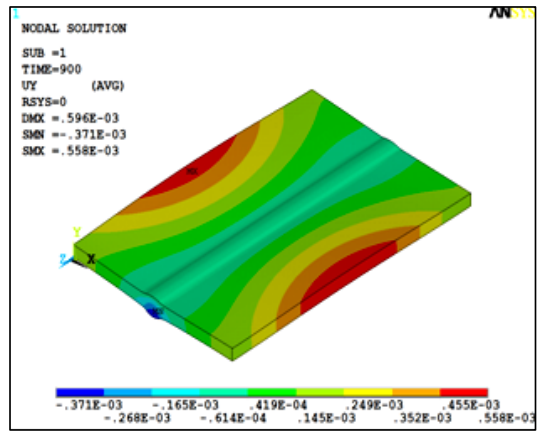

(c)

Fig. 13 (a) Distortion of Sample 1 expressed as displacement (SMX in m) in Y direction, (b) distortion of Sample 2 (SMX in $\mathrm{m}$ ) in $\mathrm{Y}$ direction and (c) distortion of Sample 3 (SMX in $\mathrm{m}$ ) in Y direction

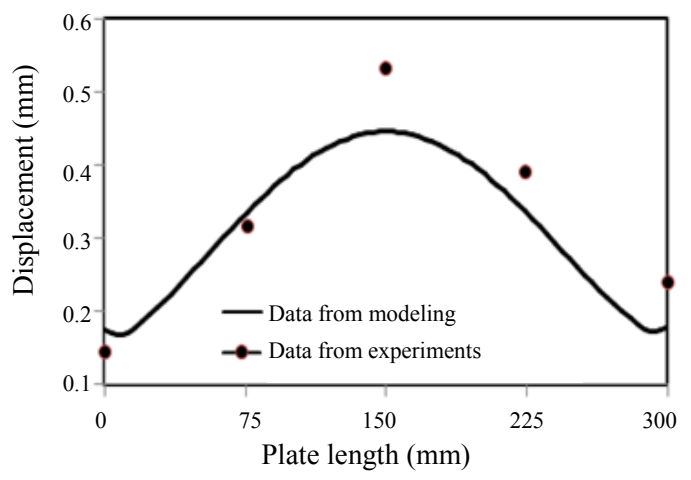

(a)

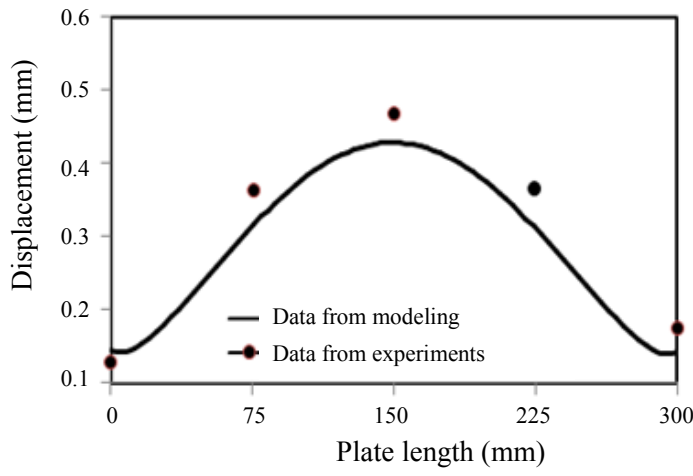

(b)

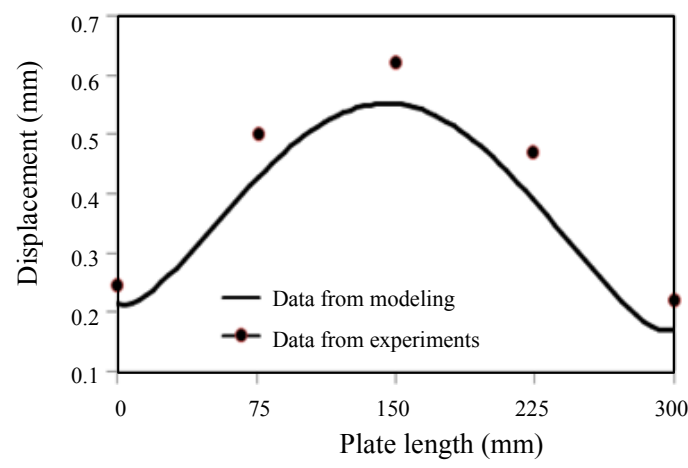

(c)

Fig. 14 (a) Comparison between experimentally observed grid point displacement (distortion) and nodal displacement (SMX in $\mathrm{m}$ in Y direction) for Sample 1, (b) Comparison of experimentally observed grid point displacement (distortion) and nodal displacement (SMX in $\mathrm{m}$ in Y direction) for Sample 2 and (c) Comparison of experimentally observed grid point displacement (distortion) and nodal displacement (SMX in $\mathrm{m}$ in Y direction) for Sample 3 
side SAW square butts can be both side welded with a possibility of slag inclusion in the joint. However, it is observed that with $32 \mathrm{~V}, 600 \mathrm{~A}$ and welding travel speed of $5.5 \mathrm{~mm} / \mathrm{s}$ more than $6 \mathrm{~mm}$ of depth of penetration can be achieved which eliminates the possibility of slag inclusion.

- This model successfully predicted the post welding heating effect of second pass weld on the first side weld. It also indicted the preheating of second pass weld due to effect of first pass weld.

- By this technique the use of costly backing bar/strip can be eliminated for thick section.

ORCID: H. K. Narang: http://orcid.org/0000-0002-1274-8003 ORCID: PVSS Sridharg: http://orcid.org/0000-0002-7344-8194 ORCID: P. Biswas: http://orcid.org/0000-0001-7069-0308

\section{References}

1. V. Kamala and J. A. Goldak, Error due to two dimensional approximation in heat transfer analysis of welds, Welding Journal, 72(9) (1993), 440s-446s

2. T. Tso-Liang, F. Chin-Ping, C. Peng-Hsiang and Y. WeiChun, Analysis of residual stresses and distortions in T-joint fillet welds, International Journal of Pressure Vessels and Piping, 78 (2001), 523-538 https://doi.org/10.1016/S0308-0161(01)00074-6

3. D. Radaj, Heat effects of welding, Springer-Verlag $\mathrm{GmbH}$, (1992)

4. P. Michaleris and A. DeBiccari, Prediction of welding distortion, Welding Journal, 76(4) (1997), 172s-80s

5. O. Muransky, C. Hamelin, M. Smith, P. Bendeich, and L. Edwards, The effect of plasticity theory on predicted residual stress fields in numerical weld analyses, Computational Materials Science, 54 (2012), 125-134 https://doi.org/10.1016/j.commatsci.2011.10.026

6. L.E Lindgren, Finite element modeling and simulation of welding Part 1: increased complexity, Journal of Thermal Stresses, 24 (2001), 141-92 https://doi.org/10.1080/01495730150500442

7. L.E. Lindgren, Finite element modeling and simulation of welding Part 2: improved material modeling, Journal of Thermal Stresses, 24 (2001), 195-231 https://doi.org/10.1080/014957301300006380

8. H. Alberg, B. Daniel, Comparison of an axisymmetric and a three-dimensional model for welding and stress relief heat treatment. In: Proceedings of the eighth international conference on numerical methods in industrial forming processes-NUMIFOFM 2004, Columbus, $\mathrm{OH}$, USA, 13-17 June 2004

9. J.U Park, H.W Lee, and H.S Bang, Effects of mechanical constraints on angular distortion of welding joints, Science and Technology of Welding and Joining, 7(4) (2002), 232-239

https://doi.org/10.1179/136217102225004266
10. T. Schenk, I. Richardson, M. Kraska, and S. Ohnimus, A study on the influence of clamping on welding distortion, Computational Materials Science, 45(4) (2009), 999-1005 https://doi.org/10.1016/j.commatsci.2009.01.004

11. M.M Mahapatra, G.L Datta, B. Pradhan, and N.R Mandal, Modeling the effects of constraints and SAW process parameters on angular distortions in one-sided fillet welds, Proceedings of the Institution of Mechanical Engineers, Part B, Journal of Engineering Manufacture, 221 (2007), 397-407 https://doi.org/10.1243/09544054JEM617

12. D. Camilleri, and T.G. McPherson, Procedural tacking fabrication influences on welding distortion, Proceedings of the International Conference on Advances in Welding Science \& Technology for Construction, Energy \& Transportation, M. Kocak, Ed., (2010), 403-408

13. M.M. Mahapatra, G.L. Datta, B. Pradhan, and N.R. Mandal, Three-dimensional finite element analysis to predict the effects of SAW process parameters on temperatures and angular distortions in single pass butt joints with top and bottom reinforcements, International Journal of Pressure Vessels and Piping, 83 (2006), 721729 https://doi.org/10.1016/j.ijpvp.2006.07.011

14. T. Kannengiesser, T. Lausch and A. Kromm, Effects of heat control on the stress build-up during high-strength steel welding under defined restraint conditions, Welding in the World, 55 (2011), 07-08, 58-65

15. A.A. Bhatti and Z. Barsoum, Development of efficient three-dimensional welding simulation approach for residual stress estimation in different welded joints, Journal of Strain Analysis for Engineering Design, 47 (2012), 539-552 https://doi.org/10.1177/0309324712463866

16. S.A. Tsirkas, P. Papanikos, K. Pericleous, N. Strusevich, F. Boitout, and J.M. Bergheau, Evaluation of distortions of laser welded shipbuilding parts using a local-global approach, Science and Technology of Welding and Joining, 8(2) (2003), 79-88

https://doi.org/10.1179/136217103225010899

17. M.M Mahapatra, G.L. Datta, and B. Pradhan, Three-dimensional finite element analysis to predict the effects of SMAW process parameters on temperature distributions and weldment zones in butt and one-sided fillet welds, Proceedings of the Institution of Mechanical Engineers, Part B, Journal of Engineering Manufacture, 220 (2006), 837-845 https://doi.org/10.1243/09544054JEM371

18. F.Z.I. Fanous, Y.A. Maher and S.A. Wifi, 3-D Finite element modeling of the welding process using element birth and element movement techniques. Transactions ASME, Journal of Pressure Vessel Technology, 125 (2003), 144-150 https://doi.org/10.1115/1.1564070

19. J. Wang, N. Ma, H. Murakawa, B. Teng and S. Yuan, Prediction and measurement of welding distortion of a 
spherical structure assembled from multi thin plates, Materials and Design, 32 (2011), 4728-4737 https://doi.org/10.1016/j.matdes.2011.06.047

20. D. Deng and H. Murakawa, Prediction of welding distortion and residual stress in a thin plate butt-welded joint, Computational Materials Science, 43(2) (2008), 353-365

https://doi.org/10.1016/j.commatsci.2007.12.006

21. D. Deng, H. Murakawa and W. Liang, Numerical simulation of welding distortion in large structures, Computer Methods in Applied Mechanics and Engineering, 196(45) (2007), 4613-4627 https://doi.org/10.1016/j.cma.2007.05.023

22. D. Deng, H. Murakawa, and W. Liang, Prediction of welding distortion in a curved plate structure by means of elastic finite element method, Journal of Materials Processing Technology, 203(2008), 252-266 https://doi.org/10.1016/j.jmatprotec.2007.10.009

23. Y. Ueda, H. Murakawa, and N. Ma, Chapter 2-Introduction to measurement and prediction of residual stresses with the help of inherent strains, Welding Deformation and Residual Stress Prevention. Boston, Butterworth Heinemann, (2002), 35-53

24. H. Murakawa, D. Deng, N. Ma, and J. Wang, Applications of inherent strain and interface element to simulation of welding deformation in thin plate structures, Computational Materials Science, 51(1) (2012), 43-52 https://doi.org/10.1016/j.commatsci.2011.06.040
25. J. Wang, M. Shibahara, X. Zhang and H. Murakawa, Investigation on twisting distortion of thin plate stiffened structure under welding, Journal of Materials Processing Technology, 212(8) (2012), 1705-1715 https://doi.org/10.1016/j.jmatprotec.2012.03.015

26. S. Brown and H. Song, Implication of three-dimensional numerical simulations of welding large structures, Welding Journal, 71(2)(1992), 55s-62s

27. M.M. Mahapatra, G.L. Datta, B. Pradhan and N.R. Mandal, Modelling of angular distortion of double-pass buttwelded plate Proceedings of the Institution of Mechanical Engineers, Part B, Journal Engineering Manufacture, 222 (2008), 391-401 https://doi.org/10.1243/09544054JEM995

28. P. Biswas and N.R. Mandal, Thermomechanical finite element analysis and experimental investigation of single-pass single-sided submerged arc welding of C-Mn steel plates, Proceedings of the Institution of Mechanical Engineers, Part B, Journal Engineering Manufacture 224(B4) (2010), 627-639 https://doi.org/10.1243/09544054JEM1624

29. E. Friedman, Thermomechanical analysis of welding process using finite element method, Transaction of ASME Journal of Pressure Vessel Technology, 97(3) (1975), 206-213 https://doi.org/10.1115/1.3454296

30. Theory reference, ANSYS Inc., Southpointe, Canonsburg, Pennsylvania, (2009) 